\title{
RESPONSABILIDAD CIVIL DEL ESTADO Y DE SUS DEPENDIENTES
}

\author{
Claudio Illanes Ríos \\ Profesor de Derecho Civil \\ Universidad de Chile
}

Indudablemente que dentro de la temática moderna el enfoque de la responsabilidad civil es una materia extraordinariamente interesante e importante, por el profundo cambio que significa este tipo de responsabilidad en función al trato tradicional que tiene la responsabilidad civil, fundamentalmente a través de nuestro Código Civil.

Como cuestión previa, es necesario dejar constancia o recordar que toda persona natural o persona jurídica que actúa a través de sus personeros administrativos, si realizan un hecho ilicito que causa perjuicio, está obligado ese ofensor a reparar el daño producido. El principio básico de tener que reparar el daño causado por la comisión de un hecho ilicito es común al ofensor, sean los particulares, corporaciones de derecho privado, como también las empresas del Estado que actúan a través de sus órganos de administración.

Respecto de los ilícitos civiles en el ámbito de las relaciones de derecho privado, se regulan normal y básicamente por la normativa existente en el Código Civil, tanto en lo que diga relación con la responsabilidad contractual como la extra contractual, sea que esa responsabilidad se genere por un hecho propio, por un hecho de dependientes, por un hecho de las cosas o de los animales.

En cuanto a la responsabilidad civil que puede producirse con ocasión de ilícitos civiles cometidos por entes administrativos de sociedades anónimas abiertas, existe un régimen jurídico especial acerca de su responsabilidad, que está fundamentalmente contenida en la ley 18.046 sobre Sociedades Anónimas y la ley 18.045 que es la Ley de Valores.

Ahora, respecto de la responsabilidad del Estado y sus agentes, no solamente se aplica en términos subsidiarios las normas generales de la responsabilidad civil, sino que en materia de responsabilidad del Estado la situación cambia radicalmente, porque esta responsabilidad está tratada en su concepción básica y fundamental no en un cuerpo legal como podría ser un Código, sino que nada menos que en la Constitución Política del Estado.

Es una de las pocas responsabilidades que tiene su fuente, su existencia directa e inmediata en la propia Constitución Política del Estado. Al efecto les recuerdo que el Art. 60 de la Constitución Política del Estado del año 1925, y actual Art. 24 de la Constitución del 80, señalan que el Gobierno y la Administración del Estado corresponde al Presidente de la República, o sea el Presidente de la República dentro de la organización de nuestro ordenamiento del Estado, es la figura más importante y es el primer responsable de toda la marcha interna y externa del país. 
Concordante con que la administración del Estado reside fundamentalmente en el Presidente de la República, quien es el que administra la Nación, el Art. 38 de la Constitución Política del Estado actualmente vigente expresa que una Ley Orgánica Constitucional determinará la organización básica de la Administración Pública, y su Inciso $2^{\circ}$ establece, aquí viene lo importante, dice: "Cualquier persona que sea lesionada en sus derechos por la Administración del Estado, de sus organismos o de las Municipalidades, podrá reclamar ante los tribunales contenciosos administrativos que determine la ley, sin perjuicio de las responsabilidades que pudieran afectar al funcionario que hubiere causado el daño." Es decir, la figura, el tipo de la responsabilidad civil del Estado a través de la actuación de sus dependientes, es de rango constitucional.

A su vez, la Ley Orgánica Constitucional dictada conforme a los preceptos de la Constitución, que corresponde a las bases generales de la administración del Estado, la ley 18.575 del año 1986 , en su Art. $4^{2}$ repite nuevamente lo que ya dispone el Art. 38 , Inciso $2^{\circ}$ al decirnos que: "El Estado será responsable por los daños que causen los órganos de la administración en el ejercicio de sus funciones, sin perjuicio de las responsabilidades que pudieran afectar al funcionario que los hubiere causado". Es decir, hay una reiteración en su Ley Orgánica del precepto constitucional.

A esto debemos agregarle un principio, que también es de gran importancia y que establece nuestra Constitución Política del Estado, que la doctrina ha denominado el principio de la legalidad.

El principio de la legalidad nosotros lo encontramos en dos preceptos de la Constitución, en el Art. $6^{\circ}$ y en el Art. $7^{\circ}$. El Art. $6^{\circ}$, en cuanto nos señala que los órganos del Estado deben someter su acción a la Constitución y las normas dictadas conforme a ello. Los preceptos de esta Constitución obligan tanto a los titulares o integrantes de dichos órganos como a toda persona, institución o grupo; y enseguida, el Art. $7^{\circ}$, en cuanto las personas deben actuar dentro de la órbita de sus atribuciones.

El principio de la legalidad establecido en la Constitución constituye un precepto básico para poder entender qué tipo de responsabilidad civil es la que consagra la Constitución para el Estado y sus órganos dependientes. del Estado?

¿Cuál es el tipo de responsabilidad civil que establece la Constitución Política

Desde luego el Inciso $2^{\circ}$ del Art. 38 , en relación con los Arts. 6 y 7 de la misma Constitución, observan que hay dos sujetos pasivos de la acción de reparación. En primer lugar, el Estado propiamente tal; esto constituye la gran novedad de la Constitución del año 1980, que establece como responsable en primer lugar por un acto ilícito cometido por una empresa del Estado a través de sus órganos dependientes, en la medida que hayan actuado en función y acorde con el principio de la legalidad, en primer lugar, al Estado mismo, el Fisco para tales efectos, por los actos que lesionen derechos ajenos. Y también señala como segundo sujeto pasivo al funcionario o agente que haya causado el daño, en cuanto el Estado tiene derecho a repetir en contra del agente o funcionario autor del hecho ilícito, pero naturalmente que este derecho de repetición no excluye lo fundamental y básico: es el Estado quien responde.

¿Cómo la doctrina ha considerado que es esta responsabilidad? Este tipo de responsabilidad es la que se denomina la responsabilidad orgánica del Estado, o sea el Estado como tal responde. 
La primera oportunidad en que ya se habló de que había una especie de responsabilidad orgánica se produce con ocasión de la Ley de sociedades anónimas, que en cierta medida toma como elemento de inspiración el Art. 38 Inciso $2^{\circ}$, y cambia el concepto tradicional que existía, en cuanto a que los directores de una sociedad anónima eran mandatarios de los accionistas que lo habían elegido, para dar lugar a la teoría del órgano, en el sentido de que el directorio de una sociedad anónima es un ente autónomo independiente de los accionistas que los han elegido, y los directores no se deben a los accionistas que los eligieron sino que se deben a la sociedad tal, y en base a esta concepción básica la Ley de Sociedades Anónimas y la Ley de Valores construye la responsabilidad global y solidaria de un directorio de una sociedad anónima, en la medida que un acuerdo tomado por ese directorio sea generador de un hecho ilícito que cause perjuicio a la sociedad, a los accionistas, a terceros o a los acreedores.

$Y$ este cambio de naturaleza jurídica del directorio de una sociedad anónima, es un efecto transversal de la teoría orgánica que ya establece la Constitución que empieza a regir el año 80 y la Ley de sociedades anónimas y de valores en el año 81 . Hay una real correspondencia y armonía en el tipo de responsabilidad que genera una ley que recoge un precepto constitucional. Responsabilidad orgánica del Estado: por primera vez este término es usado y mencionado por los Tribunales en una célebre sentencia de la Corte de Apelaciones de Santiago de 26 de Enero de 1984, que fue confirmada íntegramente por la Corte Suprema con posterioridad. Esa sentencia fue muy importante. porque es el primer fallo judicial que derechamente entra a aplicar en toda su integridad el precepto constitucional a que estamos haciendo referencia, y es el primer fallo que da una estructura a esta responsabilidad y la denomina en su fallo, una responsabilidad de tipo orgánica.

El problema se produce por la intervención que en el año 1971 se hizo al Banco Continental. Después de restablecidas las situaciones por todos conocidas, los dueños del Banco Continental iniciaron acciones civiles contra el Fisco, reclamando al Fisco o al Estado de Chile a través del Fisco, como responsable de los perjuicios que el Interventor había causado en dicho Banco al haber hecho una emisión de 20 millones de acciones que produjeron una verdadera hecatombe. Naturalmente que el primer juicio importante que era de gran cuantía, con un Banco que en esa época era muy importante, conmocionó a los Tribunales porque fue la primera oportunidad en un asunto de gran envergadura que se hacía valer esta responsabilidad.

Es interesante leer dos considerandos de este fallo, que ilustran muy bien el concepto de la Responsabilidad Orgánica del Estado. En su considerando $3^{2}$ este fallo dijo lo siguiente: "Que en relación a las afirmaciones señaladas en el motivo anterior, debe tenerse en cuenta que en la especie se trató de la emisión de 20 millones de acciones que fueron ordenadas por la Superintendencia de Bancos que es un órgano del Estado". Recuerda que quien ordenó todo esto es un órgano del Estado dependiente del Ministerio de Hacienda.

En la referida actuación, como ha quedado demostrado en la sentencia recurrida y en las consideraciones anteriores de este fallo, se hizo un uso desviado de la Ley General de Bancos existente a la época de los hechos. Se invocó para actuar un precepto de orden público como lo era el Art. 24 de la Ley General de Bancos. En la especie, no se ha tratado de una representación asumida por agentes del Estado, muy por el contrario, ha sido la intervención de un órgano del Estado, lo que equivale al Estado mismo. 
La actividad administrativa y los efectos que produce son causados por voluntad de la administración, que expresa la voluntad de la ley más no la voluntad del funcionario, la cual debe coincidir con aquella como requisito para la ilegalidad o validez de la actuación administrativa.

Más adelante el mismo considerando dice: "En lo que en doctrina se denomina la teoría organicista", -primera oportunidad que nuestros Tribunales de Justicia hacen valer el término que ampara con mayor amplitud a los administrados, puesto que tanto los actos como las omisiones, sean regulares o ilícitos, son imputables directamente a la administración- "ello se atribuye en forma directa e inmediata al órgano público, sin perjuicio de los efectos internos que la actuación ilegal o arbitraria cause entre el funcionario y la administración". Obviamente respeta el derecho de repetir contra el funcionario que produjo el hecho.

Es el primer fallo que menciona qué es la responsabilidad del Estado por falta de servicio, -a lo cual me referiré más adelante-, existente entre el agente público y la administración, dando lugar entonces a la responsabilidad administrativa, sin que quepa excusa frente al tercero respecto de quien ha actuado el Estado mismo.

$Y$ en el considerando siguiente hace un alcance muy importante en que distingue lo que es la responsabilidad orgánica del Estado, de lo que eventualmente podría tratar de configurarse como una responsabilidad civil extra contractual; el considerando 14 de este fallo dice: "Que en cuanto a que el fallo recurrido no haya señalado la fuente de responsabilidad del Estado y que en la especie no se haya acreditado el hecho ilícito civil o penal que daría lugar a la indemnización de perjuicio, cuyà reserva solicitaron los actores, debe tenerse en cuenta que en el caso de autos no se trata de la responsabilidad contractual o extra contractual derivada de un delito o cuasi delito, sino de un acto de autoridad diferente al de simple gestión", con lo cual incorpora un concepto muy valioso, que cuando estamos reclamando la responsabilidad del Estado como tal en un acto de administración que cause un ilícito civil, no estamos frente a un hecho que genera una responsabilidad extra contractual sino que estamos reclamando la responsabilidad orgánica y directa del Estado.

"Sobre el particular corresponde mencionar", -agrega el fallo-, "que en esta materia ha existido una evolución significativa de la doctrina". En efecto, en una primera etapa predominó el traslado de los principios del Código Civil de materia contractual y extra contractual. En una segunda etapa se ha ido imponiendo el principio de la legalidad propio de un Estado de derecho, que determina que el actuar del agente público debe ser dentro del marco de su competencia, por lo que existe una responsabilidad autónoma hoy perfectamente consagrada en los actuales Arts. $6^{2}$ y $7^{\circ}$ de la Constitución Política del Estado.

Por otra parte, aparece obvio que al momento de haberse interpuesto la demanda, los actores no podían tener clara la naturaleza, especie y monto de los perjuicios, razón por la cual solicitaron y obtuvieron la reserva de acciones correspondientes. Cito este fallo, porque este fallo es del año 84 , tres años después de que entra en vigencia la Constitución Política del Estado y, naturalmente, fue un caso muy espectacular porque se trataba de una gran cantidad de dinero, un juicio que conmocionó enormemente el ambiente del foro y en el que se precisó, a mi modesto entender, en forma muy correcta lo que es este nuevo tipo de responsabilidad que se genera respecto del Estado por la Constitución Política. 
Ahora, esta responsabilidad orgánica del Estado significa un cambio importante en relación a la responsabilidad común que establece nuestra legislación del Código Civil para entender este tipo de responsabilidad. Nosotros sabemos que fundamentalmente la responsabilidad civil común es de carácter subjetiva, vale decir, para que una persona sea responsable civilmente frente a otra tiene que haber habido un elemento de imputabilidad, culpa o dolo. En términos generales, no se concibe una responsabilidad sin culpa o sin dolo; excepcionalmente nuestra ley en materias muy especiales ha consagrado la responsabilidad objetiva, pero en el campo de las relaciones privadas la responsabilidad general es de carácter subjetiva y no objetiva.

En materia de las relaciones privadas, y ya vamos a ver en la responsabilidad por falta de servicio lo que ha ocurrido, siguiendo la clásica división que se hizo en Francia entre obligaciones de medios y obligaciones de resultado, se ha visto que en las obligaciones de resultado, vale decir, aquellas en que solamente es posible esperar un resultado y nada más que eso, y si ese resultado no se produce, se es responsable, hay una especie de responsabilidad objetiva.

Pues bien, en materia de responsabilidad del Estado la Constitución Política altera el principio general y consagra derechamente la responsabilidad objetiva, es decir, basta que el agente del Estado o la autoridad del Estado en un acto de administración haya realizado un hecho que causa daño, para que por esa sola circunstancia sea responsable, quedando solamente a la víctima la necesidad de tener que probar y cuantificar el daño causado, pero no tiene que entrar a probar de que la autoridad o el agente del Estado que actuó, actuó con culpa o con dolo, lo que es un cambio muy importante. porque debe recordarse que hasta antes de la Constitución del año 80 la responsabilidad civil de los agentes del Estado se manejaba por las normas de la responsabilidad extra contractual, Título 35 del Código Civil, de los Delitos y Cuasi Delitos, y particularmente por lo prevenido en el Art. 2320 del Código Civil, es decir, el Estado quedaba igualado a un particular y el Estado podía excusarse en el cumplimiento de la obligación de reparar el daño en la medida que pudiera establecer que habiendo tenido todo el cuidado y la debida diligencia, no fue capaz de impedir el hecho. En tal caso el Estado podría exonerarse de responsabilidad, le bastaba solamente con señalar que la culpa que se aplicaba era la culpa in vigilandi, si él vigilaba bien y a pesar de eso se cometía el ilícito que causaba daño, el Estado no era responsable, por lo cual obviamente la posibilidad de resarcir el daño para el particular afectado por un acto ilícito cometido por un agente del Estado en el ejercicio de sus funciones era muy difícil poderla obtener. porque siempre tenía el Estado la puerta abierta de una excusa.

La responsabilidad objetiva ha sido difundida ampliamente por la doctrina nacional y extranjera en materia de responsabilidad del Estado, y justamente por la aplicación de este concepto es por lo que se ha dado lugar a la conocida como responsabilidad por falta de servicio, que es tal vez uno de los aspectos más importantes y más corrientes en que se tenga que hacer efectiva esta responsabilidad orgánica del Estado.

En primer lugar tendríamos que decir y señalar qué ha dicho la doctrina y la jurisprudencia en cuanto a lo que debe entenderse por falta de servicio.

En general la doctrina ha sido bastante lacónica y con buen criterio no ha querido entrar en grandes concepciones, porque probablemente una conceptualidad muy ampulosa podría dar margen a las excepciones y contra excepciones. En términos muy sencillos la jurisprudencia se ha ido uniformando respecto de lo siguiente: ha dicho que 
hay falta de servicio en toda deficiencia o mal funcionamiento de un servicio público que ocasiona un daño. Algo bastante simple y categórico: toda deficiencia o mal funcionamiento, evitando de caer en una conceptualización demasiado detallada que en definitiva permita eludir la responsabilidad del Estado, buscándole sentidos y alcances diversos a la conceptualización que haya hecho el sentenciador en algunos fallos.

Han existido algunos grupos de situaciones en los que se ha hecho palpable esta responsabilidad por falta de servicio.

Por una parte, los daños ocasionados por deficiencias o mal funcionamiento de servicios que están a cargo de las Municipalidades. Les recuerdo que las Municipalidades están incluidas en el Art. 38 de la Constitución Política. Y también donde la indemnización por falta de servicio ha tenido jurisprudencia en estos últimos años ha sido por problemas derivados del ejercicio de la salud pública, a través de Establecimientos de Salud del Estado.

He traído algunos fallos que he seleccionado. Hay un caso que se vio en la Corte de Valparaíso "Quezada con Servicio de Salud", fallo del año 1992. Solamente leo la parte de interés de un considerando que dice lo siguiente: "Que en la doctrina se han planteado diversas teorías con respecto a la forma como se vincula jurídicamente el poder público y los individuos, y consiguientemente, la manera como los actos de la administración son imputables u oponibles directamente al Estado. Una de tales teorías es la llamada teoría del órgano". Noten que ya casi 8 años después la expresión responsabilidad del órgano se dice en las sentencias judiciales con entera propiedad y sin temor, doctrina que se sustenta sobre disposiciones constitucionales y legales, las que debidamente coordinadas dan lugar a un "sistema integral y cohesionado". Debidamente integrado y cohesionado es una expresión que me gustó mucho de este fallo porque no excluye las normas comunes establecidas en la ley, principalmente en el Código Civil, y aquí también anuncia una concepción muy importante dentro de una interpretación moderna del Derecho, que es la integración de la ley a un precepto constitucional. Ese precepto constitucional puede ser integrado por un precepto legal, o un precepto legal puede ser reforzado por un precepto constitucional, es decir, si hay duda en cómo debe entenderse un precepto legal, y ese precepto legal en alguna forma tiene el mismo bien jurídico que el precepto constitucional está protegiendo, no hay ninguna duda de que ese precepto legal debe entenderse y aplicarse con rango constitucional.

De allí que para la teoría organicista las consecuencias derivadas de la actuación irregular de un funcionario como asimismo los daños causados a terceros, dan lugar a la responsabilidad administrativa. Las faltas o arbitrariedades $u$ omisiones cometidas por un funcionario público hacen responsable directamente a la Administración frente a los administrados.

Hay otro fallo también en esa misma dirección, que es del año 95, causa "Uribe y otros con Fisco". Me parece interesante lo que se dice aquí, en relación con un problema de salud como es el Sida.

Hay dos considerandos que dicen lo siguiente: el primero de estos considerandos que es el derecho a la salud de doña Fulana de Tal y de su hijo don Fulano de Tal, infectado con el virus del Sida, fue conculcado por el Estado por razón de la falta de servicio en que incurrió el Ministerio de Salud al no dotar oportuna y adecuadamente a los servicios respectivos de los implementos y reactivos necesarios para detectar el virus 
$\mathrm{VIH}$, virus de inmunodeficiencia humana. $\mathrm{Y}$ el otro considerando dice que no es elemento de la falta de servicio la negligencia oculta, que sí lo es tratándose de la responsabilidad extra contractual. Vuelve a repetir aquí que estamos frente, por una parte, a una responsabilidad objetiva, una obligación de resultado y en consecuencia no es, no se está buscando la negligencia o el hecho culposo o doloso, ni tampoco se está pensando en una responsabilidad de tipo extra contractual. Y agrega que el Art. 22484 del Código Civil señala como requisito del cuasi delito, la culpa, en cambio tratándose de la falta de servicio el Art. $4^{2}$ de la ley 8.575 (que es la Ley Orgánica sobre Bases de la Administración del Estado), tal requisito no se consigna por el legislador, ya que esta responsabilidad administrativa es de carácter objetivo. Por otro lado, el Art. $4^{Q}$ de la ley 18.575 habria sido innecesariamente dictado si la responsabilidad del Estado hubiese sido ya regida por las normas del Título 35 del Libro IV. del Código Civil que trata De los Delitos y Cuasi Delitos.

Esta consideración es de gran valor porque es la defunción definitiva de ese Titulo, en cuanto pretenda aplicársele en la responsabilidad orgánica del Estado, con lo cual lo que ya se había supuesto y se había pensado (que ya no era posible el Estado asilarse en el Art. 2320 y siguientes para poder exculparse de las omisiones cometidas por sus agentes en el ejercicio de sus funciones), este fallo categóricamente lo dice. Por consiguiente ya hoy día está absolutamente afianzado que en la responsabilidad del Estado no se está persiguiendo una responsabilidad extra contractual, no debe acreditarse la negligencia culpable del agente del Estado sino que basta solamente acreditar el daño.

Tengo aqui seleccionada también una causa de carácter médico. En honor de la verdad, aun cuando el hecho fue bastante repudiable en sí mismo y la persona de que se trata era en esa época Ministro de la Corte Suprema (sr. Leonel Beraud), es justo reconocer que tanto la sentencia del Ministro de Fuero que se designó, que fue Cornelio Villarroel, como la sentencia de la Corte Suprema posterior que modificó la cuantificación del daño, están absolutamente ajustadas en la concepción doctrinaria y jurídica que corresponde a la responsabilidad del Estado.

Tan es asi que no hay nada nuevo en este fallo, que sea absolutamente distinto a lo que ya se venía señalando sobre el particular, de modo que no se puede decir que por tratarse de un Ministro de la Corte Suprema los Tribunales Superiores de Justicia hayan acomodado un determinado tipo de responsabilidad, o imbuidos de un espíritu creativo espontáneo para hacer justicia a uno de sus pares, hayan exacerbado el sentido correcto de la ley para crear una doctrina que haya sido flor de un día.

Pero lo importante es que aquí se reiteran algunos principios; en la letra c) del considerando 16 de la sentencia del Ministro de Fuero se dice que de las antedichas disposiciones se desprende que para que surja el derecho de cualquier persona para reclamar ante los Tribunales de Justicia y para que nazca para el Estado la obligación correlativa de resarcir o indemnizar el daño-este fallo es importante porque todavía no se había planteado el problema de la titularidad de la acción y no se había reparado que el Art. 38-, se requiere al menos la concurrencia de los siguientes requisitos: que la persona titular del derecho a reclamo haya sufrido un daño o lesión de alguno de sus derechos, que la lesión al derecho particular del reclamante se haya producido por la Administración del Estado, de sus organismos o de las Municipalidades, y que los órganos de la administración hayan actuado en el ejercicio de sus funciones. 
Este considerando lo he seleccionado porque es un considerando que estableció un contexto de referencia. Hasta el momento, en ninguno de los fallos anteriores se había establecido con claridad cuáles eran los presupuestos básicos que deberían reunirse para poder ser titular de la acción. Esa cualquier persona tiene que haber sufrido un daño o lesión en alguno de sus derechos, o sea un daño real, efectivo, porque no es indemnizable un daño meramente eventual, hipotético o conjetural. Tiene que haberse producido un daño o lesión en algún derecho de una persona, porque la responsabilidad del Estado no solamente se refiere a hechos que producen un daño en bienes corporales, sino que también es posible que el daño se produzca en bienes incorporales o derechos subjetivos. Por ejemplo, que un agente del Estado o de sus organismos, en el ejercicio de sus funciones, impida a un particular ejercer una facultad que la ley le ha concedido. "De sus organismos": expresión muy correcta, por la responsabilidad en particular de las empresas del Estado o de las Municipalidades, siempre que los órganos de la administración hayan actuado en el ejercicio de sus funciones, obviamente, porque si un agente se sale de sus funciones y actúa por su cuenta obviamente que no puede comprometer al Estado.

En el fallo de la Corte Suprema -que es bastante largo-, he seleccionado nada más que dos conceptos: "En efecto, el Art. $4^{\circ}$ de la ley 18.575 contiene un mandato objetivo de responsabilidad que grava al Estado por la sola circunstancia que el daño producido lo haya sido con motivo de la actuación de un órgano determinado de la administración y en el ejercicio de las funciones de éste".

$Y$ en otro considerando se dice que el Fisco puede excepcionarse de responsabilidad por el caso fortuito. Pero en mi modesta opinión, no hay ningún indicio en la Constitución Política del Estado y en la Ley de Bases Generales de la Administración del Estado de que el caso fortuito sea un elemento capaz de interrumpir el nexo causante, no aparece de la fórmula contenida en la Constitución que ese nexo causal pueda ser roto por el evento del caso fortuito.

Hay un interesantísimo trabajo del Profesor Jorge López Santa María sobre este asunto. El sostiene que el caso fortuito podría ser invocado en circunstancias excepcionalísimas, pero que hay que tomar en cuenta que Chile el año 1984 suscribió la Convención de Viena, en la cual se acordaron, por seguridad mundial, una serie de responsabilidades de Estado en que no cabe alegar el caso fortuito. Con esto Jorge López hace ver una tesis generalizada: que en la responsabilidad del Estado habría una especie de elemento que agrava la responsabilidad.

Entre los efectos prácticos que se derivan de la aplicación de la teoría del órgano, se encuentra el de servir de fundamento jurídico para imputar al Estado o a las demás personas jurídicas de derecho público, la responsabilidad por los perjuicios ocasionados a los derechos e intereses legítimos de los administrados a consecuencia de la actividad de los órganos integrantes. Dicha imputación es posible sea que la causa del daño provenga de actuaciones materiales, intelectuales o técnicas, de actos administrativos, de omisiones, de retardos, del funcionamiento parcial o imperfecto, y también si la causa del daño es la actividad irregular o la actividad regular y lícita de los órganos públicos. Hay una obligación de resultado; a mi no me interesa si el agente actuó bien o actuó mal, actuó en forma regular o irregular, lo que sí me interesa es que el daño se causó y el daño no debió haberse causado, por lo cual el Estado responde. 
Indudablemente que todos estos fallos ya permiten ir configurando una situación que hoy día está fuera de la discusión, en orden a que hay una responsabilidad objetiva, directa del Estado en la medida que se cumplan estos requisitos que estableció la Corte Suprema. 